\title{
Leptin: role over central nervous system in epilepsy
}

\author{
Laura Mora-Muñoz, Alejandro Guerrero-Naranjo, Elisa Angélica Rodríguez-Jimenez, \\ Claudio Alberto Mastronardi and Alberto Velez-van-Meerbeke* (D)
}

\begin{abstract}
Adipose tissue is a dynamic organ with different effects on the body. Many of these effects are mediated by leptin, a hormone strongly involved in regulation of feeding and energy metabolism. It has an important role as a mediator of neuronal excitatory activity and higher brain functions. The aim of this study was to review the association between leptin and cerebral neuronal function, in particular its anticonvulsant or convulsant effects and the possible therapeutic role for treating epilepsy. For this purpose, the databases Pubmed, Science Direct, Elsevier, ResearchGate and Scielo were searched to identify experimental studies, reviews and systematic review articles, published in English, Spanish or Portuguese. Experimental studies and the presence of leptin receptors in nervous system sites other than the hypothalamus suggest an influence on higher brain functions. Indeed several animal studies have demonstrated a role of these channels in epileptiform activity as both anticonvulsive and convulsive effects have been found. The reason for these discrepancies is unclear but provides clear evidence of a potential role of leptin and leptin therapy in epileptiform activity. The association between leptin and brain function demonstrates the importance of peripheral metabolic hormones on central nervous system and opens a new way for the development of novel therapeutic interventions in diseases like epilepsy. Nevertheless further investigations are important to clarify the dynamics and diverse actions of leptin on excitatory regulation in the brain.
\end{abstract}

Keywords: Leptin, Adipose tissue, Nervous system, Hypothalamus, Epilepsy, Anticonvulsants, Convulsants

\section{Background}

The central nervous system (CNS), specifically the hypothalamus, acts as a sensor of storage and energy expenditure. Adipocytes, the most important functional unit of adipose tissue, secrete adipokines, such as leptin, that regulate energy balance [1]. Although the role of leptin at the hypothalamic level to regulate food intake and energy balance is well established, its participation on higher brain functions remains to be elucidated. For instance, there is evidence showing that leptin can act both as anticonvulsant and convulsant trigger [1].

Epilepsy is a chronic neurological disorder experienced by approximately fifty million people around the world. Its prevalence in the general population is $4-10$ per 1000

\footnotetext{
*Correspondence: Alberto.velez@urosario.edu.co Escuela de Medicina y Ciencias de la Salud, Universidad del Rosario, Cra 24 No 63C-69, Bogotá, Colombia
}

people, while in low and middle-income countries is higher (7-14 per 1000 people) [2]. Whereas active epilepsy (defined as a history of more than one unprovoked seizure and either recent seizures in the previous 5 years or current use of antiepileptic medication), is 12.4 per 1000 people ranging from 5.1/1000 to 57/1000 [3-5]. The incidence of epilepsy range between 30 and 50 per 100,000. In 2012, 20.6 billion disability adjusted life years (DALYs) were due to epilepsy [2].

The objective of this article was to analyze the possible effects of leptin on the pathophysiology of epilepsy, comparing the findings of animal models, which demonstrated both convulsive and non-convulsive actions. To contextualize the review, we described the molecular characteristics of leptin, its various isoforms, the receptors in the central nervous system, the signaling pathway in nervous cells, the role and functions of leptin within

C The Author(s) 2018. This article is distributed under the terms of the Creative Commons Attribution 4.0 International License (http://creativecommons.org/licenses/by/4.0/), which permits unrestricted use, distribution, and reproduction in any medium, provided you give appropriate credit to the original author(s) and the source, provide a link to the Creative Commons license, and indicate if changes were made. The Creative Commons Public Domain Dedication waiver (http://creativecommons.org/ publicdomain/zero/1.0/) applies to the data made available in this article, unless otherwise stated. 
the CNS affecting higher brain functions, and/or showed the specific actions related to the mechanism of epilepsy.

A review of literature was carried out. The following databases were consulted: Pubmed, Science Direct, Elsevier ResearchGate and Scielo. Eligibility criteria were: experimental studies, reviews and systematic review articles; that were selected if the publication date between January 1997 and January 2018; restricted to non-human studies and articles published in English, Spanish and Portuguese. Research was made through the Medical Subject Headings (MESH) terms: MeSH keywords in Pubmed: ((("Epilepsy”[Mesh]) AND "Leptin”[Mesh]) OR "Adipose Tissue"[Mesh]) OR "Hypothalamus"[Mesh]. The same search terms were adapted for Science Direct, Elsevier ResearchGate and Scielo electronic databases. The corresponding Health Sciences Descriptors in Spanish (DeCS) terms were also used. Exclusion criteria were studies outside the range of proposed dates and studies made in humans.

Two authors (LMM, AGN) independently evaluated the eligibility of all studies by checking the title and the abstract to determine whether they met all of the inclusion criteria. Disagreements were resolved by discussion or consultation with other authors (AVM). When they were ambiguous, the complete articles were analyzed to determine their pertinence. A total of 226,925 articles were identified through databases searching using the
MESH an DECS terms (Fig. 1). Consecutively, the articles were selected based on title, abstract, and, in text information. Based on these criteria, a total of 65 articles were chosen.

As a meta-analysis was not performed due to the characteristics and heterogeneity of the articles, a narrative report was done extracting the most important information of each article.

\section{Leptin: a pleiotropic hormone}

Leptin, a 16-kDa protein encoded by the Ob gene, regulates body weight, reduces appetite, and controls food intake. Insulin, glucocorticoids, leptin and other hormones regulate expression of this protein. It appears that several metabolic actions are controlled through FOSL2, a key transcription factor that regulates leptin expression in the adipocyte [6-8].

There are six isoforms of the leptin receptor (Ob$\mathrm{Ra}, \mathrm{Ob}-\mathrm{Rb}, \mathrm{Ob}-\mathrm{Rc}, \mathrm{Ob}-\mathrm{Rd}, \mathrm{Ob}-\mathrm{Re}$ and OB-Rf) that result from RNA alternative splicing. According to their domains, are classified in short, long and secreted [9]. $\mathrm{Ob}-\mathrm{Rb}$ stands out as the only receptor type showing a full-length intracellular domain containing 304 residues, which gives it the ability to activate intracellular signaling cascades. Once leptin binds to Ob-Rb, it elicits the auto-phosphorylation of Janus kinase -2 (JAK- 2), a non-receptor tyrosine kinase that is associated with the

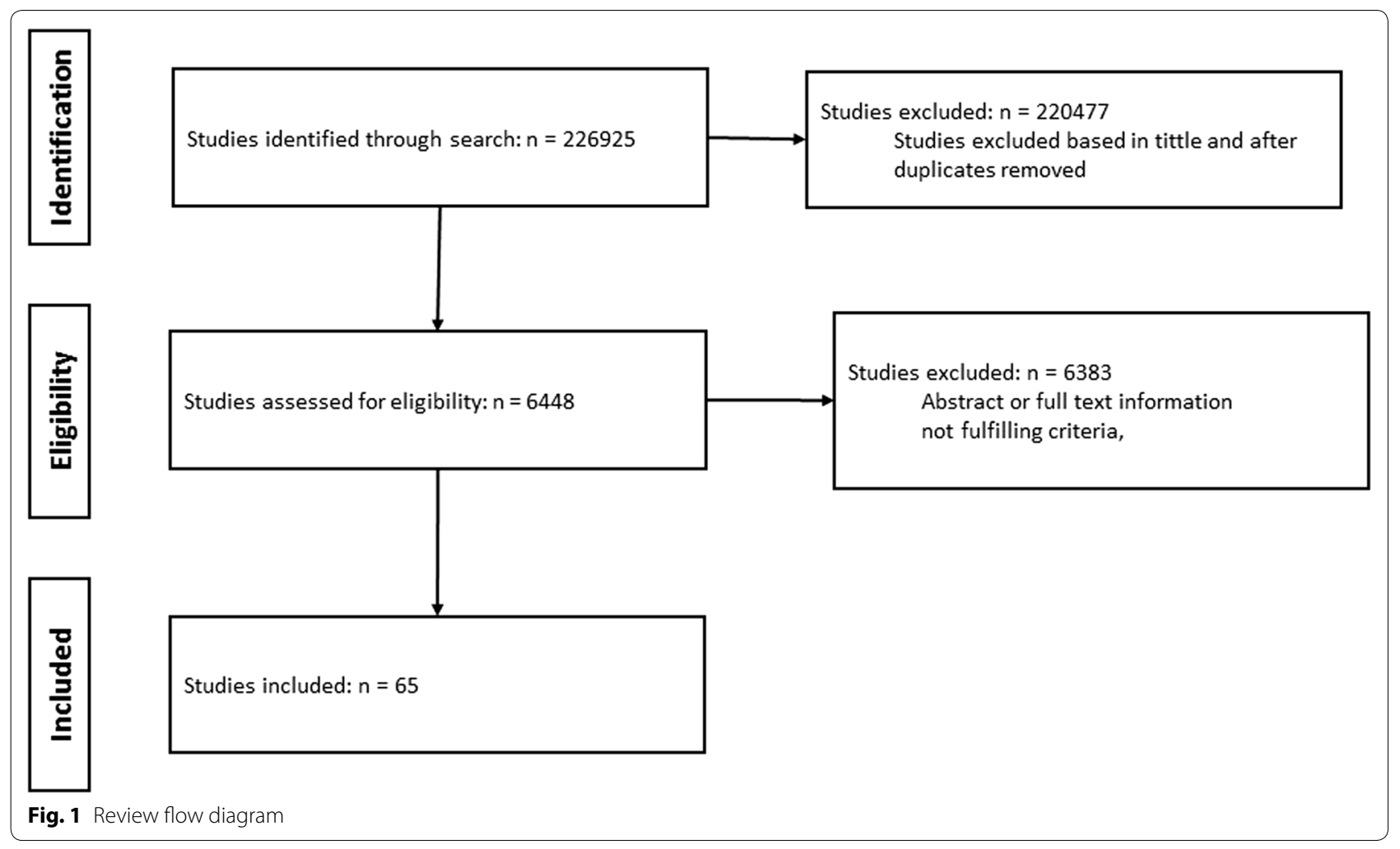


$\mathrm{Ob}-\mathrm{Rb}$ receptor. Thereafter, JAK- 2 phosphorylates tyrosine (Tyr) residues of the intracellular domain of $\mathrm{Ob}-\mathrm{Rb}$, and depending on the Tyr residue that is phosphorylated it can trigger different types of intracellular responses [1, 9] (Fig. 2).

In the case that Tyr 985 is phosphorylated, it will lead to the recruitment of Src homology 2 domain (SH2), triggering a signaling cascade mediated by extracellular signal-regulated kinase (ERK) [9]. The SH2-containing tyrosine-specific protein phosphatase (SPH2), and "SH2 domain-containing adaptor, the growth factor receptorbinding protein" (GRB2), enable ERKs phosphorylation [10]. Its activation has been related to energy homeostasis, as long as its blockage incurs in a disruption in the induction of sympathetic activation of BAT and a deregulation of its anorexic, and weight controlling actions [11].

On the other hand, if Tyr 1077 residue is phosphorylated, it leads to signal transducer and activator of transcription 5 (STAT -5) activation, whereas if Tyr 1138 residue is phosphorylated, it will lead to STAT 3 activation. STAT phosphorylation leads to the dimerization and its subsequent translocation to the nucleus, coordinating the transcription of genes involved in energy balance such as proopiomelanocortin (POMC) [1, 9]. $\mathrm{POMC}$ is a protein that can be cleaved to render the anorexigenic $\alpha$-melanocyte stimulating hormone $(\alpha-\mathrm{MSH})$, which constitutes the major target of this pathway [9]. It is noteworthy to remark that STAT 3 also plays a significant role in controlling the transcription of genes that are implicated in leptin signaling, such as suppressor of cytokine signaling 3 (SOCS3), a key negative regulator of leptin effects, by inhibiting leptin- STAT3 signaling [12].

Activation of phosphatidylinositol-4, 5-bisphosphate 3-kinase (PI3K) by the Insulin Receptor Substrate complex, is also induced. PI3 $\mathrm{K}$ mediates the signaling of leptin in hypothalamic neurons, regulating neuro electrical effects on POMC neurons. This enzyme phosphorylates PIP2 (phosphatidylinositol-4,5-bisphosphate) and forms PIP3 (phosphatidylinositol-3,4,5-triphosphate), which links the activity of PI3 $\mathrm{K}$ with important downstream pathways, like Akt-FoxO1 and Akt-mTOR [9]. Interestingly, as demonstrated, leptin can inhibit different forms of epileptiform-like activity via PI3 K pathway [13].

The activity of Akt within the Akt- mammalian target of rapamycin1 (mTORC1) pathway allows the activation of mTORC1 mainly by various mechanisms that have been subject to extensive study. mTOR activation is related with leptin action in the hypothalamus [14]. Leptin increases hypothalamic mTOR activity, and this the serine-threonine kinase, through its downstream target Ribosomal protein S6 kinase beta (S6K1), phosphorylates $\alpha 2$-AMPK. In consequence the activity of

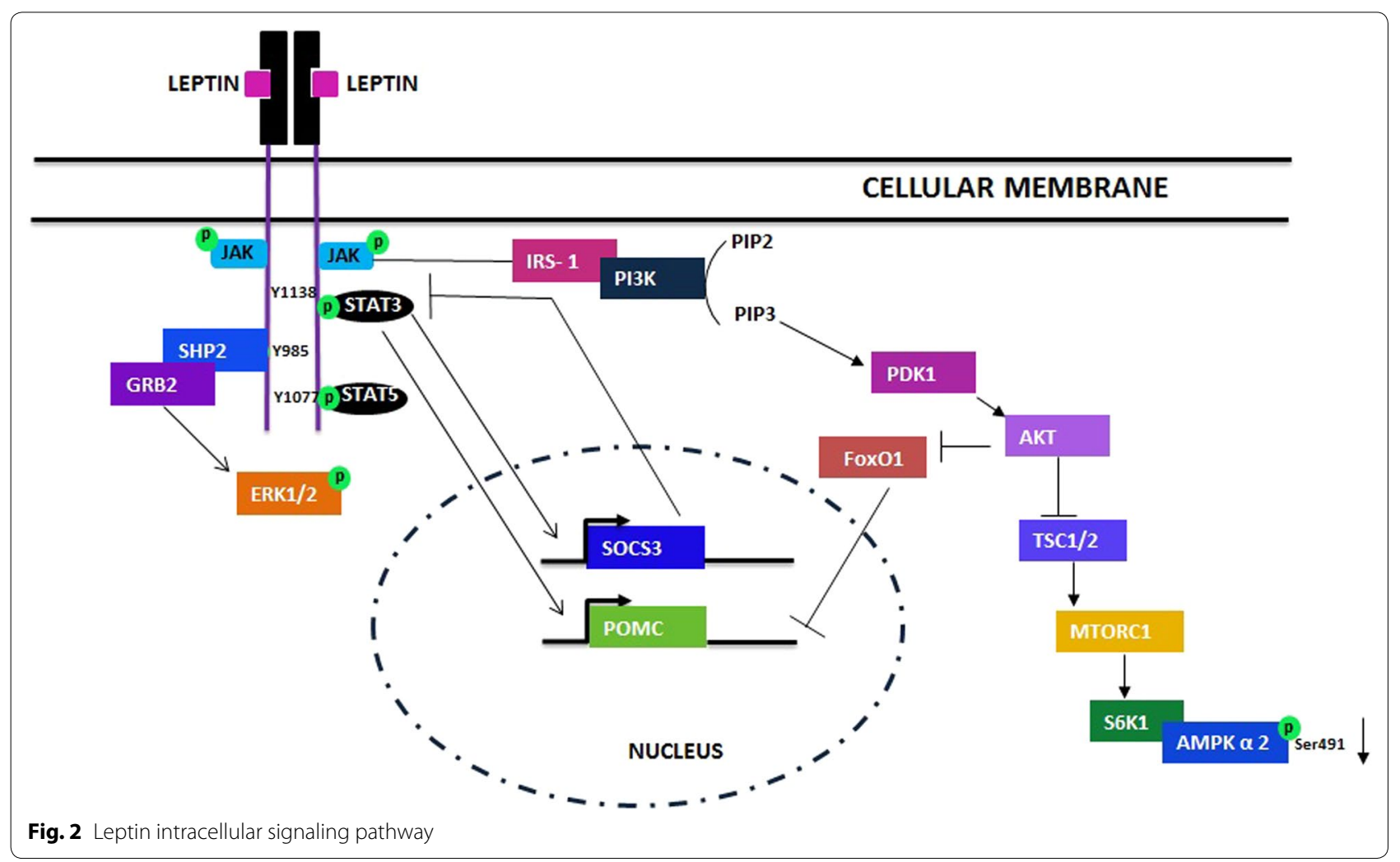


leptin decreases food intake and body weight. Additionally, mTOR mediates the anorexigenic, sympathetic and cardiovascular effects of leptin [9].

\section{Leptin and central nervous system}

As it was mentioned above, leptin plays key roles within the hypothalamus to control food intake and energy expenditure. However, there is also evidence suggesting that leptin could be involved in other neurological processes in extra-hypothalamic sites. Interestingly, within the hippocampus leptin was associated with both anticonvulsant and convulsant effects, and it was also shown to act as neurotrophic factor that promotes neurogenesis [7, 15-17].

Leptin has been strongly associated with the regulation of neuronal excitability in different regions of the CNS $[18,19]$. It modulates cell excitation by activating large conductance $\mathrm{Ca}^{+}$-activated potassium channels (BK channels) within the hippocampus and by stimulating ATP-sensitive potassium channels (KATP channels) during its regulatory metabolic functions within the hypothalamus and insulin-secreting cells [20-22]. The latter, highlights the anorexigenic leptin functions that are well described in the literature. However, mounting evidence also suggest other central actions of leptin in multiple sclerosis, amyotrophic lateral sclerosis, Alzheimer, that remain to be better understood [23-25].

There is evidence showing association between leptin and high brain functions, such as cognition and memory; for example, higher leptin levels are associated with a lower risk of incident dementia and Alzheimer's disease (AD) [26]; leptin improves memory and serves as disease modifying therapeutic in transgenic mouse models of $A D$ [27]; leptin receptor-deficient rodents have impairments in spatial memory and alterations in LTP and LTD in hippocampal CA1 neurons[28]; physiological increases in leptin levels facilitate the CaMK II activity in the hippocampus, which induces LTP, contributing to memory and learning[29]; and leptin facilitate spatial learning and hippocampal LTP in mice [30]. In vivo studies in rodents reported that leptin can increase the proportion of dendrites enabling morphological changes that can promote the formation of new synaptic connections within the hippocampus $[17,31]$. The latter suggested that leptin may have an important therapeutic role in neurodegenerative diseases such as epilepsy. In fact, it has been established that the effects of leptin-based therapeutic strategies are potentially useful for patients with diverse diseases, besides congenital metabolic leptin deficiency disorders, such as mood disorders, Alzheimer's disease and autism [30, 32-34].

Interestingly, some studies have explored the role of astrocytes in the activity of leptin on the CNS. These glial cells express various $\mathrm{Ob}-\mathrm{R}$ subtypes. When some of them are overexpressed, changes have been demonstrated in leptin permeability through an in vitro blood brain barrier system, suggesting that astrocytes might be involved in the entrance of leptin into the CNS [35]. In mice, with specific mutations that inhibit expression of $\mathrm{Ob}-\mathrm{R}$ in astrocytes (ALKO Mice-astrocyte specific leptin receptor knockout mice) studies have shown that astrocytes can intervene significantly in neuronal leptin-induced signaling [36].

Jayaram et al. [37] found that leptin may have glioprotective effects in a mouse model of seizures induced by pilocarpine administration. This model found that ALKO mice had a lower survival rate and that administration of leptin, under gliotoxicity when exposed to high levels of glutamate, exerted a protective effect on astrocytes [37]. These results suggest that leptin can have a protective role against excitotoxicity when presented during epilepsy.

At this point, it is important to note that the peripheral effects of leptin may have relevant implications on susceptibility to epilepsy. The dysfunction of the adipose tissue and the hormones that it produces, such as leptin, supposes a susceptibility to neurodegenerative diseases associated with obesity and metabolic disorders, since the neuroprotective effects that have been evidenced in the actions of leptin could be influenced by the resistance to leptin that is characteristic of disorders such as obesity, decreasing it's neuroprotective effect and contributing to the pathogenesis of different neurodegenerative diseases, such as AD [38, 39]. In addition, obesity causes metabolic changes that alter the expression of leptin receptors in astrocytes, generating underlying alterations in the functions of glial cells that would have serious implications for leptin homeostasis as previously mentioned [36, 40]. In fact, models with adult-onset obesity mice have shown that obesity induces an increase in ObR levels in astrocytes and ObRb mRNA in the cerebral microvasculature [41], and that astrocytes play regulatory roles on the dynamics of leptin in the hypothalamus, since its inhibition improves the signaling and uptake of leptin by neurons [42]. Finally, it should be noted that obesity implies the occurrence of a sufficiently important level of peripheral inflammation, which could be mediated by the action of leptin and could contribute significantly to the development of neuroinflammation and oxidative stress in the central nervous system, increasing the susceptibility to the occurrence of neurodegenerative diseases, such as epilepsy [39, 43, 44].

It would be interesting to determine the possible effects that antiepileptic drugs (AEDs) have on the role of leptin on CNS. Weight gain is associated with changes in secretion and behavior of leptin and it is a major side effect of 
these drugs. It is relevant to assess whether the actions on neuronal excitability of this hormone, both positive and negative, could be involved in the evolution of epilepsy before consumption of AEDs [45-48].

\section{Experimental models: anticonvulsant and convulsant effects of leptin (see Additional file 1)}

In recent decades, the relationship between the effect of leptin on the CNS and epilepsy has been recognized as a new and viable association that could lead to future effective alternatives to treat this disorder. Experimental animal studies conducted around this association have generated results that begin to unravel the potential therapeutic effects of leptin on metabolic and neurodegenerative diseases $[1,18,19]$.

\section{Anticonvulsant studies}

Shanley et al. [13] demonstrated in cultured hippocampal neurons of rats, previously exposed to a $\mathrm{Mg}^{2+}$-free medium to cause synchronous spontaneous $\mathrm{Ca}^{2+}$ oscillations, that application of leptin significantly reduced overall $\mathrm{Ca}^{2+}$ levels, in a reversible manner. To assess whether the mechanism of action of leptin depended on the activation of KATP channels or on the activation of BK channels, inhibitors of these channels were applied separately. The results showed that glybenclamide and glipizide (KATP channel inhibitors) had little effect on the ability of leptin to decrease calcium levels, while the application of iberiotoxin and charybdotoxin (BK channels inhibitors) significantly blocked the effect of leptin. Therefore, the conclusion was that leptin blocks epileptiform-like activity through activation of BK channels. This is consistent with the regulation of neuronal excitability that BK channels exert and their protective function in some types of epilepsy [49].

In-vivo studies in rodents have opened new perspectives on the therapeutic potential of leptin in epilepsy. $\mathrm{Xu}$ et al. [50] tested the efficacy of leptin in two seizure models. First, they demonstrated that leptin injected directly into the motor area of cerebral cortex of anesthetized 4-6 week old male rats, decreased the frequency and duration of focal seizures induced by the administration of 4-aminopyridine. In the second model, generalized seizures were induced by intraperitoneal injection of pentylenetetrazol (PTZ) in 6-8 weeks old male rats and intranasal leptin was administered. The results showed increased levels of brain and serum leptin and increased latency of convulsive seizures. Additionally, authors found that leptin inhibited synaptic response in hippocampal brain slices, in a U-shaped concentration manner and by selective inhibition of AMPA receptors.
The above results are particularly relevant because AMPA receptors mediate fast synaptic excitation and hyper-synchronization in the pathophysiology of epilepsy [51], and, as showed by Xu et al. [50], leptin inhibits synaptic AMPAergic responses by activating the JAK/PI3K pathway, suggesting that leptin could act as a good anticonvulsant agent in the treatment of epilepsy by reducing epileptiform activity, similar to the action of AMPA receptor antagonists [51].

Complementing the above results, models of epilepsy induced by PTZ demonstrated that ob/ob mice deficient in leptin have increased severity of seizures compared with wild-type mice [52]. Video electroencephalogram recordings showed an increased susceptibility to tonicclonic and clonic generalized seizures, more deaths and a higher percentage of epileptiform activity.

In order to identify the underlying mechanisms of the anticonvulsant effects of leptin, experimental studies focused on the potential role of phosphoinositide 3 kinase (PI3K), a common intermediate of leptin signaling, downstream from the activated leptin receptors (ObRb). Administration of LY294002 and wortmannin (PI3K inhibitors) reduced the effect of leptin over the decrease in spontaneous calcium oscillations and over hippocampal synaptic response, supporting the involvement of JAKs [13]. The results reinforce the idea that these intracellular pathways are important in the anticonvulsant action of leptin. Furthermore, electrophysiological studies carried out on hippocampal slices of rodents with deficiency in these receptors (Obese Zucker fa/fa rats and $\mathrm{db} / \mathrm{db}$ mice) showed that leptin action was dependent on $\mathrm{Ob}-\mathrm{Rb}$ when compared with slices of control rodents $[13$, 50].

Previous experiments have proposed neuroprotective effects of leptin in a model of status epilepticus induced by kainic acid in rodents [53]. The researchers found that leptin attenuates the degeneration of hippocampal neurons, in both acute and chronic stages. However, the effects of leptin doses were restricted only to histological results, because the occurrence of recurrent spontaneous seizures or behavioral long-term deficits could not be avoided. Interestingly, a study demonstrated that leptin treatment soon after the induction of neonatal status epilepticus in rats counteracted the long-term alterations associated to hyperexcitability, supporting leptin's neuroprotective effects and its potential therapeutic roles [54].

Consistent with the relationship with the innate immune system, inflammation and oxidative stress in the process of epileptogenesis, Oztas et al. [55] evaluated the effect of leptin in a convulsive seizure model. They showed that the administration of leptin, in addition to causing anticonvulsant effects, reduce levels of pro-inflammatory cytokines suggesting a crucial 
anti-inflammatory role of leptin in epilepsy. Furthermore, leptin significantly increased the levels of galanin, a neuropeptide that has anti-excitatory properties. Regarding oxidative stress, leptin administration produced a reduction in the serum levels of malondialdehyde and an increase of glutathione, which correlates with possible protective effects against oxidative damage during epilepsy.

\section{Convulsant studies}

Although anticonvulsants effects of leptin have been well documented, this hormone can also have convulsant actions. Using a rat model of epileptiform activity induced by penicillin, Ayyildiz found a dose-dependent effect of leptin to increase the frequency of the penicillininduced epileptiform activity [56]. An intracerebroventricular of $1 \mu \mathrm{g}$ of penicillin administered was the most effective dose in changing the frequency on penicillininduced epileptiform activity.

Similarly, a study assessing the convulsant or anticonvulsant effects of leptin before the administration of glutamate or NMDA, AMPA and kainate receptor agonists in mice, showed an increased percentage of seizures, and a decreased latency in the onset of seizures in the groups that received NMDA or kainate receptor agonists together with leptin. The authors concluded that leptin exerted a convulsant activity [57].

Nitric oxide (NO) might have an essential role in epilepsy due to its properties as a second messenger, neuromodulator and neurotransmitter in the central nervous system. The literature shows an ambiguous dual action (convulsive or anticonvulsive) of NO. A kainate-induced epileptic model showed that NO end-product levels and seizure activity increased after kainate injection, and both were attenuated with the administration of the NOS inhibitor 7-nitroindazole (7-NI), suggesting that epileptic activity may be related with NO [58]. In contrast, studies that investigated the role of $\mathrm{NO}$ as a neuromodulator in the anticonvulsant effects of pyridoxine on penicillin-induced epileptiform activity didn't find evidence of involvement of NOS activity in the brain, even though it was demonstrated that 7-NI by itself reduced the epileptiform activity [59]. With the aim to determine whether the convulsant effect of leptin could be related to nitric oxide, Aslan et al. induced epileptiform activity in rats through the injection of penicillin with the subsequent administration of leptin. The intervention increased significantly the frequency of epileptiform activity in relation with those animal with penicillin only [60]. In the presence of leptin, the anticonvulsant effect of 7-nitroindazole (selective inhibitor of neuronal nitric oxide synthase (NOS)) or L-arginine (nitric oxide precursor) was delayed significantly. However in the presence of NG nitro-L-arginine methyl ester (L-NAME) which is a nonselective inhibitor of NOS did not influence proconvulsant activity of leptin. This suggests that neuronal NOS pathway could effectively make part of the underlying convulsant mechanism elicited by leptin in this model. The mechanism of action of L-arginine on the effect of leptin is not fully understood. However, it has been shown previously that the administration of $\mathrm{L}$-arginine alone decreases the epileptiform activity caused by penicillin, and it has been proposed that perhaps it could compete with leptin for the binding sites associated with the regulation of NO production $[61,62]$.

The interaction of the cannabinoid system and the effect of leptin in the CNS has been studied in relation with its anorexigenic properties and metabolic functions [63-65]. However, the anticonvulsant properties of the cannabinoid system has also been widely documented. Blair et al. showed in primary hippocampal neuronal culture models of acquired epilepsy and status epilepticus that the cannabinoid receptor agonist WIN 55,212-2 produced dose-dependent anticonvulsant effects on both models, in a CB1 receptor-dependent manner [66]. In concordance, it has been shown that administration of SR-141716A and AM-251, CB1 receptors antagonists, generated status epilepticus-like activity in a hippocampal neuronal culture model of acquired epilepsy, which is reversible with application of CB1 agonists [67]. Furthermore, in an amygdala-kindling model of temporal lobe epilepsy, Wendt et al. found that the CB1 receptor agonist WIN 55,212-2 delayed the progression of seizure severity on kindling acquisition [68]. They also found that administration of URB597, an inhibitor of the enzymatic degradation of the endocannabinoid anandamide, reduced the amount of newborn neurons during the kindling process, suggesting a disease-modifying effect of the endocannabinoid system. The involvement of cannabinoids on neuronal excitability allows to consider a possible relation with leptin effects.

Through an experimental model of epileptiform activity induced by penicillin, using electrocorticographic recordings, Arslan et al. found that administration of leptin restricted anticonvulsant activity of arachidonyl2-chloroethylamide, a cannabinoid type 1 receptor (CB1) agonist, and increased the convulsant effect of AM-251, a CB1 receptor antagonist [69]. Therefore, the results indicated that inhibition of $\mathrm{CB} 1$ receptors probably mediate the convulsant effects of leptin.

\section{Conclusions}

This paper systematically reviewed research articles that examined the association between Leptin and the Nervous system, specially its effects as anticonvulsant or proconvulsant. 
Leptin can act as a neuroprotective agent that inhibits epileptiform like activity. The JAK/PI3K signaling pathway and BK channels have been associated with the anticonvulsant effects of leptin. However, more studies are required to elucidate all the intracellular pathways that leads to the mechanism of action of leptin. In concordance, chronic leptin deficiency increases brain excitability. These anticonvulsant effects of leptin have been shown in epileptic models induced by 4 aminopyridine, pentylenetrazole and in cultures exposed to stimulation in $\mathrm{Mg}^{2+}$-free medium. Paradoxically, leptin has a convulsant effect, increasing the epileptiform activity after its administration, in epileptic models induced by penicillin and glutamate receptor agonists.

Anticonvulsants and convulsant effects of leptin evidenced in various experimental studies, demonstrate the need to continue studying the role of leptin in epilepsy to analyze whether certain experimental conditions could influence the results, or if instead there are intrinsic factors of the CNS that determine the effect of leptin. In this regard, it should be taken into account the conditions in which surgery was performed, the route and amount of leptin injection, and especially the length of the postoperative period before the experiments are conducted due to the fact that animals lose weight after surgery with a consequent reduction of serum leptin concentration.

The interaction between peripheral metabolic hormones, such as leptin, and higher brain functions that could influence epilepsy allows to consider potential novel therapeutic alternatives to face this neurodegenerative condition. Therefore, it is important to conduct more studies to determine the influence of leptin on the pathophysiology of epilepsy to better understand its mechanism of action and to shed light on its therapeutic potential and its possible benefits when compared with AEDs.

\section{Additional file}

Additional file 1. Experimental model studies of leptin. Description of data: Comparative data of anticonvulsant and convulsant effects of leptin experimental model studies 1.

\footnotetext{
Abbreviations

LMM: Laura Mora-Muñoz; AGN: Alejandro Guerrero Naranjo; AVM: Alberto Velez-van-Meerbeke; EARJ: Elisa Angélica Rodríguez-Jimenez; CM: Claudio Mastronardi; CNS: central nervous system; MESH: Medical Subject Headings; DeCS: Health Sciences Descriptors (Descriptores Ciencias de la Salud); WAT : white adipose tissue; BAT: brown adipose tissue; JAK- 2: Janus kinase -2; SH2: Src homology 2 domain; ERK: extracellular signal-regulated kinase; $\mathrm{SPH} 2$ : SH2-containing tyrosine-specific protein phosphatase; GRB2: growth factor receptor-binding protein; STAT -5: signal transducer and activator of transcription 5; STAT -3: signal transducer and activator of transcription 3; a -MSH: a-melanocyte stimulating hormone; POMC: proopiomelanocortin; SOCS3: suppressor of cytokine signaling 3; KATP channels: ATP-sensitive potassium
}

channels; BK channels: $\mathrm{Ca}^{+}$-activated potassium channels; mTOR: mammalian target of rapamycin; ALKO Mice: astrocyte specific leptin receptor knockout mice; PI3K: phosphoinositide 3 kinase; NO: nitric oxide; 7-NI: NOS inhibitor 7-nitroindazole; NOS: neuronal nitric oxide synthase.

\section{Authors' contributions}

LMM, AGN and AVM analyzed the literature. LMM, AGN, EARJ, AVM wrote the manuscript. AVM and CM revised the final version of the manuscript. The authors carefully considered the BMC guidelines, and have read and approved the final manuscript. All authors read and approved the final manuscript.

\section{Competing interests}

The authors declare they have no competing interests.

\section{Availability of data and materials}

All relevant data are contained within the paper and the Additional files. The articles used can be obtained from the cited journals.

\section{Consent to publish}

Not applicable.

Ethics approval and consent to participate

Not applicable.

\section{Publisher's Note}

Springer Nature remains neutral with regard to jurisdictional claims in published maps and institutional affiliations.

Received: 31 May 2018 Accepted: 29 August 2018

Published online: 05 September 2018

\section{References}

1. Doherty $\mathrm{GH}$. Obesity and the ageing brain: could leptin play a role in neurodegeneration? Curr Gerontol Geriatr Res. 2011;2011:8.

2. Organization WH. Epilepsy. Geneva: World Health Organization; 2016.

3. Burneo JG, Tellez-Zenteno J, Wiebe S. Understanding the burden of epilepsy in Latin America: a systematic review of its prevalence and incidence. Epilepsy Res. 2005;66(1-3):63-74.

4. Meyer AC, Dua T, Ma J, Saxena S, Birbeck G. Global disparities in the epilepsy treatment gap: a systematic review. Bull World Health Organ. 2010;88(4):260-6.

5. Organization PAH. Report on Epilepsy in Latin America and the Caribbean. Washington DC: Pan American Health Organization; 2013.

6. Jequier E. Leptin signaling, adiposity, and energy balance. Ann N Y Acad Sci. 2002;967:379-88.

7. Wrann CD, Eguchi J, Bozec A, Xu Z, Mikkelsen T, Gimble J, et al. FOSL2 promotes leptin gene expression in human and mouse adipocytes. J Clin Invest. 2012;122(3):1010-21.

8. Li J, Li S, Hu Y, Cao G, Wang S, Rai P, et al. The expression level of mRNA, protein, and DNA methylation status of FOSL2 of Uyghur in XinJiang in Type 2 diabetes. J Diabetes Res. 2016;2016:5957404.

9. Kwon O, Kim KW, Kim MS. Leptin signalling pathways in hypothalamic neurons. Cell Mol Life Sci. 2016;73(7):1457-77. https://doi.org/10.1007/ s00018-016-2133-1.

10. Tups A, Stohr S, Helwig M, Barrett P, Krol E, Schachtner J, et al. Seasonal leptin resistance is associated with impaired signalling via JAK2-STAT3 but not ERK, possibly mediated by reduced hypothalamic GRB2 protein. J Comp Physiol B. 2012;182(4):553-67.

11. Rahmouni K, Sigmund CD, Haynes WG, Mark AL. Hypothalamic ERK mediates the anorectic and thermogenic sympathetic effects of leptin. Diabetes. 2009:58(3):536-42.

12. Guo Z, Jiang H, Xu X, Duan W, Mattson MP. Leptin-mediated cell survival signaling in hippocampal neurons mediated by JAK STAT3 and mitochondrial stabilization. J Biol Chem. 2008;283(3):1754-63.

13. Shanley LJ, O'Malley D, Irving AJ, Ashford ML, Harvey J. Leptin inhibits epileptiform-like activity in rat hippocampal neurones via PI 3-kinasedriven activation of BK channels. J Physiol. 2002;545(Pt 3):933-44. 
14. Harlan SM, Guo DF, Morgan DA, Fernandes-Santos C, Rahmouni K. Hypothalamic mTORC1 signaling controls sympathetic nerve activity and arterial pressure and mediates leptin effects. Cell Metab. 2013;17(4):599-606.

15. Diano S, Horvath TL. Anticonvulsant effects of leptin in epilepsy. J Clin Invest. 2008;118(1):26-8.

16. Zhou N, Rungta RL, Malik A, Han H, Wu DC, MacVicar BA. Regenerative glutamate release by presynaptic NMDA receptors contributes to spreading depression. J Cereb Blood Flow Metab. 2013;33(10):1582-94

17. Harvey J. Leptin regulation of neuronal morphology and hippocampal synaptic function. Front Synaptic Neurosci. 2013;5:3.

18. Harvey J. Leptin: a diverse regulator of neuronal function. J Neurochem. 2007;100(2):307-13.

19. Harvey J. Leptin regulation of neuronal excitability and cognitive function. Curr Opin Pharmacol. 2007;7(6):643-7.

20. Kieffer TJ, Heller RS, Leech CA, Holz GG, Habener JF. Leptin suppression of insulin secretion by the activation of ATP-sensitive $\mathrm{K}^{+}$channels in pancreatic beta-cells. Diabetes. 1997;46(6):1087-93.

21. Spanswick D, Smith MA, Groppi VE, Logan SD, Ashford ML. Leptin inhibits hypothalamic neurons by activation of ATP-sensitive potassium channels. Nature. 1997;390(6659):521-5.

22. Shanley LJ, Irving AJ, Rae MG, Ashford ML, Harvey J. Leptin inhibits rat hippocampal neurons via activation of large conductance calciumactivated K+ channels. Nat Neurosci. 2002:5(4):299-300.

23. Perez-Gonzalez R, Alvira-Botero MX, Robayo O, Antequera D, Garzon $M$, Martin-Moreno AM, et al. Leptin gene therapy attenuates neuronal damages evoked by amyloid-beta and rescues memory deficits in APP/PS1 mice. Gene Ther. 2014;21(3):298-308.

24. Lim MA, Bence KK, Sandesara I, Andreux P, Auwerx J, Ishibashi J, et al. Genetically altering organismal metabolism by leptin-deficiency benefits a mouse model of amyotrophic lateral sclerosis. Hum Mol Genet. 2014;23(18):4995-5008.

25. Kraszula L, Jasinska A, Eusebio M, Kuna P, Glabinski A, Pietruczuk M. Evaluation of the relationship between leptin, resistin, adiponectin and natural regulatory $T$ cells in relapsing-remitting multiple sclerosis. Neurol Neurochir Pol. 2012:46(1):22-8.

26. Lieb W, Beiser AS, Vasan RS, Tan ZS, Au R, Harris TB, et al. Association of plasma leptin levels with incident Alzheimer disease and MRI measures of brain aging. JAMA. 2009;302(23):2565-72.

27. Greco SJ, Bryan KJ, Sarkar S, Zhu X, Smith MA, Ashford JW, et al. Leptin reduces pathology and improves memory in a transgenic mouse model of Alzheimer's disease. J Alzheimers Dis. 2010;19(4):1155-67.

28. Li XL, Aou S, Oomura Y, Hori N, Fukunaga K, Hori T. Impairment of longterm potentiation and spatial memory in leptin receptor-deficient rodents. Neuroscience. 2002;113(3):607-15.

29. Oomura Y, Hori N, Shiraishi T, Fukunaga K, Takeda H, Tsuji M, et al. Leptin facilitates learning and memory performance and enhances hippocampal CA1 long-term potentiation and CaMK II phosphorylation in rats. Peptides. 2006;27(11):2738-49.

30. Paz-Filho G, Wong ML, Licinio J. The procognitive effects of leptin in the brain and their clinical implications. Int J Clin Pract. 2010;64(13):1808-12.

31. O'Malley D, MacDonald N, Mizielinska S, Connolly CN, Irving AJ, Harvey J. Leptin promotes rapid dynamic changes in hippocampal dendritic morphology. Mol Cell Neurosci. 2007;35(4):559-72.

32. Paz-Filho G, Mastronardi CA, Licinio J. Leptin treatment: facts and expectations. Metabolism. 2015;64(1):146-56.

33. Lu XY. The leptin hypothesis of depression: a potential link between mood disorders and obesity? Curr Opin Pharmacol. 2007;7(6):648-52.

34. Hamzawy MA, El-Ghandour YB, Abdel-Aziem SH, Ali ZH. Leptin and camel milk abate oxidative stress status, genotoxicity induced in valproic acid rat model of autism. Int I Immunopathol Pharmacol. 2018;32:2058738418785514

35. Pan W, Hsuchou H, Jayaram B, Khan RS, Huang EY, Wu X, et al. Leptin action on nonneuronal cells in the CNS: potential clinical applications. Ann NY Acad Sci. 2012:1264:64-71.

36. Wang Y, Hsuchou H, He Y, Kastin AJ, Pan W. Role of astrocytes in leptin signaling. J Mol Neurosci. 2015;56(4):829-39.

37. Jayaram B, Khan RS, Kastin AJ, Hsuchou H, Wu X, Pan W. Protective role of astrocytic leptin signaling against excitotoxicity. J Mol Neurosci. 2013:49(3):523-30.
38. Davis C, Mudd J, Hawkins M. Neuroprotective effects of leptin in the context of obesity and metabolic disorders. Neurobiol Dis. 2014;72 Pt A:61-71.

39. Lee EB. Obesity, leptin, and Alzheimer's disease. Ann N Y Acad Sci. 2011:1243:15-29.

40. Hsuchou H, He Y, Kastin AJ, Tu H, Markadakis EN, Rogers RC, et al. Obesity induces functional astrocytic leptin receptors in hypothalamus. Brain. 2009;132(Pt 4):889-902.

41. Pan W, Hsuchou H, He Y, Sakharkar A, Cain C, Yu C, et al. Astrocyte leptin receptor $(\mathrm{ObR})$ and leptin transport in adult-onset obese mice. Endocrinology. 2008;149(6):2798-806.

42. Pan W, Hsuchou H, Xu C, Wu X, Bouret SG, Kastin AJ. Astrocytes modulate distribution and neuronal signaling of leptin in the hypothalamus of obese A vy mice. J Mol Neurosci. 2011;43(3):478-84.

43. Scotece M, Conde J, Lopez V, Lago F, Pino J, Gomez-Reino JJ, et al. Adiponectin and leptin: new targets in inflammation. Basic Clin Pharmacol Toxicol. 2014;114(1):97-102

44. Ho YH, Lin YT, Wu CWJ, Chao YM, Chang AYW, Chan JYH. Peripheral inflammation increases seizure susceptibility via the induction of neuroinflammation and oxidative stress in the hippocampus. J Biomed Sci. 2015;22:46

45. Lagace DC, McLeod RS, Nachtigal MW. Valproic acid inhibits leptin secretion and reduces leptin messenger ribonucleic acid levels in adipocytes. Endocrinology. 2004;145(12):5493-503.

46. Aydin K, Serdaroglu A, Okuyaz C, Bideci A, Gucuyener K. Serum insulin, leptin, and neuropeptide y levels in epileptic children treated with valproate. J Child Neurol. 2005;20(10):848-51.

47. Sonmez FM, Zaman D, Aksoy A, Deger O, Aliyazicioglu R, Karaguzel $\mathrm{G}$, et al. The effects of topiramate and valproate therapy on insulin, c-peptide, leptin, neuropeptide $Y$, adiponectin, visfatin, and resistin levels in children with epilepsy. Seizure. 2013;22(10):856-61.

48. Ozcelik AA, Serdaroglu A, Bideci A, Arhan E, Soysal S, Demir E, et al. The effect of topiramate on body weight and ghrelin, leptin, and neuropeptide-Y levels of prepubertal children with epilepsy. Pediatr Neurol. 2014:51(2):220-4.

49. Bentzen BH, Olesen SP, Ronn LC, Grunnet M. BK channel activators and their therapeutic perspectives. Front Physiol. 2014;5:389.

50. Xu L, Rensing N, Yang XF, Zhang HX, Thio LL, Rothman SM, et al. Leptin inhibits 4-aminopyridine- and pentylenetetrazole-induced seizures and AMPAR-mediated synaptic transmission in rodents. J Clin Invest. 2008;1 18(1):272-80

51. Rogawski MA. AMPA receptors as a molecular target in epilepsy therapy. Acta Neurol Scand Suppl. 2013;197:9-18.

52. Erbayat-Altay E, Yamada KA, Wong M, Thio LL. Increased severity of pentylenetetrazol induced seizures in leptin deficient ob/ob mice. Neurosci Lett. 2008;433(2):82-6.

53. Obeid M, Frank J, Medina M, Finckbone V, Bliss R, Bista B, et al. Neuroprotective effects of leptin following kainic acid-induced status epilepticus. Epilepsy Behav. 2010;19(3):278-83.

54. Ni H, Chen SH, Li LL, Jin MF. Leptin treatment prevents long-term abnormalities in cognition, seizure threshold, hippocampal mossy fiber sprouting and ZnT3/CB-D28 kexpression in a rat developmental "twist" seizure model. Epilepsy Res. 2018;139:164-70.

55. Oztas B, Sahin D, Kir H, Eraldemir FC, Musul M, Kuskay S, et al. The effect of leptin, ghrelin, and neuropeptide-Y on serum Tnf-Alpha, II-1 beta, II-6, Fgf-2, galanin levels and oxidative stress in an experimental generalized convulsive seizure model. Neuropeptides. 2017;61:31-7.

56. Ayyildiz M, Yildirim M, Agar E, Baltaci AK. The effect of leptin on penicillininduced epileptiform activity in rats. Brain Res Bull. 2006;68(5):374-8.

57. Lynch JJ 3rd, Shek EW, Castagne V, Mittelstadt SW. The proconvulsant effects of leptin on glutamate receptor-mediated seizures in mice. Brain Res Bull. 2010;82(1-2):99-103.

58. Yasuda H, Fujii M, Fujisawa H, Ito H, Suzuki M. Changes in nitric oxide synthesis and epileptic activity in the contralateral hippocampus of rats following intrahippocampal kainate injection. Epilepsia. 2001;42(1):13-20.

59. Bosnak M, Ayyildiz M, Yildirim M, Agar E. The role of nitric oxide in the anticonvulsant effects of pyridoxine on penicillin-induced epileptiform activity in rats. Epilepsy Res. 2007;76(1):49-59.

60. Aslan A, Yildirim M, Ayyildiz M, Guven A, Agar E. Interaction of leptin and nitric oxide pathway on penicillin-induced epileptiform activity in rats. Brain Res. 2010:1321:117-24. 
61. Ayyildiz M, Yildirim M, Agar E. The involvement of nitric oxide in the anticonvulsant effects of alpha-tocopherol on penicillin-induced epileptiform activity in rats. Epilepsy Res. 2007;73(2):166-72.

62. Calapai G, Corica F, Corsonello A, Sautebin L, Di Rosa M, Campo GM, et al. Leptin increases serotonin turnover by inhibition of brain nitric oxide synthesis. J Clin Invest. 1999;104(7):975-82.

63. Di Marzo V, Goparaju SK, Wang L, Liu J, Batkai S, Jarai Z, et al. Leptin-regulated endocannabinoids are involved in maintaining food intake. Nature. 2001:410(6830):822-5

64. Jo YH, Chen YJ, Chua SC Jr, Talmage DA, Role LW. Integration of endocannabinoid and leptin signaling in an appetite-related neural circuit. Neuron. 2005;48(6):1055-66.

65. Thanos PK, Ramalhete RC, Michaelides M, Piyis YK, Wang GJ, Volkow ND. Leptin receptor deficiency is associated with upregulation of cannabinoid 1 receptors in limbic brain regions. Synapse. 2008;62(9):637-42.
66. Blair RE, Deshpande LS, Sombati S, Falenski KW, Martin BR, DeLorenzo RJ. Activation of the cannabinoid type-1 receptor mediates the anticonvulsant properties of cannabinoids in the hippocampal neuronal culture models of acquired epilepsy and status epilepticus. J Pharmacol Exp Ther. 2006;317(3):1072-8.

67. Deshpande LS, Sombati S, Blair RE, Carter DS, Martin BR, DeLorenzo RJ. Cannabinoid CB1 receptor antagonists cause status epilepticus-like activity in the hippocampal neuronal culture model of acquired epilepsy. Neurosci Lett. 2007;411(1):11-6.

68. Wendt H, Soerensen J, Wotjak CT, Potschka H. Targeting the endocannabinoid system in the amygdala kindling model of temporal lobe epilepsy in mice. Epilepsia. 2011;52(7):e62-5.

69. Arslan G, Alici SK, Ayyildiz M, Agar E. The role of CB1-receptors in the proconvulsant effect of leptin on penicillin-induced epileptiform activity in rats. CNS Neurosci Ther. 2013;19(4):222-8.
Ready to submit your research? Choose BMC and benefit from:

- fast, convenient online submission

- thorough peer review by experienced researchers in your field

- rapid publication on acceptance

- support for research data, including large and complex data types

- gold Open Access which fosters wider collaboration and increased citations

- maximum visibility for your research: over $100 \mathrm{M}$ website views per year

At BMC, research is always in progress.

Learn more biomedcentral.com/submissions 